\title{
Influence of different types of sugars in physalis jellies
}

\author{
Paula Nogueira CURI ${ }^{1}$, Cynara dos Santos CARVALHO ${ }^{2}$, Derlyene Lucas SALGADO², Rafael PIO ${ }^{1}$, \\ Moacir PASQUAL ${ }^{1}$, Filipe Bittencourt Machado de SOUZA ${ }^{1}$, Vanessa Rios de SOUZA ${ }^{2 *}$
}

\begin{abstract}
The objective of this study was to evaluate the influence of different types of sugar (white refined sugar, white crystal sugar, demerara sugar, brown sugar and coconut sugar) on the physicochemical characteristics, rheological properties and sensory acceptance of physalis (Physalis L) jelly. In addition, we evaluated the influence of the information on the acceptability of the product. It was found that the type of sugar greatly influences the physicochemical and rheological characteristics of physalis jelly which reflects differences in the product acceptability. Due to higher sensory acceptance, white refined, white crystal and demerara sugars are the most suitable for processing jellies. It was also found that the sugar type information and its benefits has no significant influence on sensory acceptance of physalis jelly and that consumers have a preference for a clearer, less sweet, more acidic and softer jelly.
\end{abstract}

Keywords: Physalis peruviana; white sugar; demerara sugar; brown sugar; coconut sugar; processing.

Practical Aplications: It was possible to verify which types of sugars in physalis are more suitable for jelly processing.

\section{Introdution}

Consumers are increasingly concerned about health and thus interest in the consumption of healthier foods is increasing. Within this context a demand has emerged for replacing the traditional white cane sugar by more natural and probably healthier sugars (Struck et al., 2014). The substitution of the type of sugar is associated with significant changes in texture, color, flavor and shelf life (Souza et al., 2013), so it is a challenge to find suitable replacements which result in satisfactory products (Riedel et al., 2015).

Sugar is an essential component in the elaboration of products such as preserves, jams and jellies and sucrose is normally used in its white refined or crystal form (Jackix, 1988). However, to obtain white sugar, especially during the extracting and refining stages, some additives are added such as clarifier agents and preservatives that remain, at least in part, in the products to which they are added and depreciate the nutritional quality (Mendonça et al., 2000). The white crystal sugar is composed of large, transparent or slightly yellow crystals. After extraction of sugarcane juice, purification, evaporation and crystallization, this sugar undergoes a slight refinement stage where it loses many of its minerals. By being economical and 'going a long way', white crystal is one of the most used sugars (Rodrigues et al., 1998). White refined sugar is obtained from the purification of white crystal sugar. It features fine, irregular grains which easily dissolve in beverages and other preparations. In refining, chemical additives, such as sulfur, are used to give a whiter color to the sugar.
The demerara and brown sugars, extracted from sugarcane, would be two sugar options that are more natural than the traditional white sugar. As they practically do not undergo refinement steps and addition of chemicals, they are probably nutritionally richer sugars having a chemical composition very similar to sugarcane juice. Brown sugar is a raw sugar, dark and moist, a type of unrefined sugar with a strong molasses flavor produced by dehydrating sugarcane juice (Asikin et al., 2014). Its energy contribution is lower than that of refined sugar, but with much higher amounts of minerals, such as potassium, magnesium, iron and calcium. A great number of works emphasize that the cane brown sugar is a valuable nutritional product from the sugarcane industry (Asikin et al., 2014, 2016). This sugar contain various phytochemicals that are derived from the extracted raw material from the sugarcane and are responsible for their biological potential with beneficial effects on human health (Jaffé, 2012)

There are also commercially available sugars extracted from other sources, such as coconut sugar, which is considered one of the healthiest sugars. It is a natural sugar made from sap, which is the sugary circulating fluid of the coconut plant (Apriyantono et al., 2002). This sugar is in the form of large crystals with a brownish appearance. As it does not go through the industrial refinement process, the coconut sugar retains quite a bit of the nutrients found in the coconut palm, so this sugar contains several nutrients, such as the minerals iron, zinc, calcium and potassium and vitamins $B_{1}, B_{2}, B_{3}$ and $B_{6}$, some short chain fatty acids, polyphenols and antioxidants, which may also provide some health benefits. 
Therefore, given the increasing consumer demand for healthier products, the objective of this study was to evaluate the influence of different types of sugar (white refined, white crystal sugar, demerara sugar, brown sugar and coconut sugar) on the physicochemical characteristics, rheological properties and sensory acceptance of physalis jelly.

The preparation of preserves, jams and jellies from healthier sugars, such as demerara, brown and coconut sugar, is justified only if the product has high added value, due to the possible increase in production costs that these sugars can require. Physalis, for being an exotic, fine fruit with added value and nutritionally rich, was chosen in this study.

The physalis (Physalis $\mathrm{L}$ ), within the ranking of small fruits, is classified as a fine fruit and has excellent nutritional properties due to its functional and nutraceutical properties (Rodrigues et al., 2013). They are fruits that present high vitamin A, B and C levels, and are rich in poly-unsaturated acids, including linoleic, oleic, linolenic and palmitic acids, proteins, minerals and carotenoids (Bravo et al., 2015). The Physalis peruviana L. species stands out for being economical and producing high nutritional value fruit with high antioxidant activity (Takimoto et al., 2014).

\section{Materials and methods}

\subsection{Ingredients}

The jellies were prepared from with cultivar Physalis Peruviana with 5 types of sugars: white refined cane sugar, white crystal cane sugar, demerara cane sugar or raw cane sugar, natural brown cane sugar and coconut sugar.

The fruits were harvested in the Fruit Sector of the Agriculture Department of the Federal University of Lavras, Lavras, MG (Brazil), at their physiological maturity, determined by color and fruit size, and were immediately transported to the Post Harvest Laboratory of the Federal University of Lavras, Minas Gerais, Brazil and cold-stored until processing time. In addition to the fruit, sucrose and high-methoxyl pectin (Danisco, SP, Brazil) were used for the preparation of the jellies. Citric acid was not added because the fruits showed a suitable $\mathrm{pH}$ for processing (average of 3.5).

\subsection{Jelly processing}

Five physalis jelly formulations were prepared and the variation among them was the type of sugar used. The preparation of the jelly and juice was conducted in the Plant Product Processing Laboratory. After discarding the fruit with physical or microbiological damage and manual removal of leaves, the physalis were washed in potable water. To obtain the pulp used in the jelly preparation the fruits were homogenized with $50 \%$ water for about $5 \mathrm{~min}$ in a POLI LS-4 industrial blender with a $4.0 \mathrm{~L}$ capacity at $3500 \mathrm{rpm}$ (Metalúrgica Siemsen Ltda, Brusque, Brazil). The percentages of ingredients used for preparation of the jellies were $60 \%$ clarified physalis juice, $40 \%$ sugar and $0.5 \%$ high methoxyl pectin. For the preparation of jellies, sugar was added in the fruit pulp and then the processing was carried out in an open pan heated by a gas flame (Macanuda, SC, Brazil). After boiling, pectin was added. At the end of the process, when the soluble solids reached $65^{\circ}$ Brix, heating was stopped. The total soluble solids were determined using an RT- 82 portable refractometer. The hot jellies were poured into sterile $250 \mathrm{~mL}$ glass vials and stored at $7{ }^{\circ} \mathrm{C}$ until analysis.

\subsection{Physical and physicochemical analysis}

To characterize the physalis, the analysis of length, diameter, mass, total soluble solids, total acidity, SS/total acidity (ratio), $\mathrm{pH}$, texture and color $\left(\mathrm{L}^{*}, \mathrm{a}^{*}\right.$ and $\left.\mathrm{b}^{*}\right)$, chroma and ${ }^{\circ} \mathrm{Hue}$ were made in the fresh fruits. In the jellies, soluble solids, $\mathrm{pH}$, total acidity, color $\left(\mathrm{L}^{\star}, \mathrm{a}^{*}, \mathrm{~b}^{*}, \mathrm{C}^{\star}\right.$ and hue $)$ and texture profile analyses (TPA) were conducted. The analyses were performed in the Post Harvest Laboratory in three repetitions.

The total acidity, soluble solids and $\mathrm{pH}$ values were determined according to the Adolfo Lutz Institute (Instituto Adolfo Lutz, 2005). The color was determined according to the method described by Gennadios et al. (1996).

For fruit firmness, we measured the force required for a $3 \mathrm{~mm}$ probe coupled to a digital penetrometer, Instrutherm PTR-300. The results expressed in Newtons (N). The fruit length and diameter were measured with the aid of a $150 \mathrm{~mm}$ digital caliper (Kingtools, São Paulo, SP), and average fruit weight was determined by individual weighing of each fruit on a AUX220 semi - analytical scale, (Shimadzu of Brazil, São Paulo, SP).

The texture profile analyses (TPA) of the jellies was cinducted using a Stable Micro Systems TA-XT2i texturometer (Goldaming, England). The parameters analyzed were hardness, adhesiveness, springiness, cohesiveness, gumminess and chewiness (Friedman et al., 1963; Bourne, 1968; Van Vliet, 1991).

\subsection{Sensory analysis}

Sensory analysis was performed in the Sensory Analysis Laboratory. To evaluate the influence of the information two sensory acceptance analysis sessions were conducted for the five elaborated physalis jellies. On the first day the tasters were not informed about the sugar types used in the preparation of the physalis jellies, however, on the second day the types of sugars were identified and the health benefits of each were also presented.

The acceptance test was conducted with 80 consumers per day (50 women and 30 men), among them students and office staff between 18 and 40 years of age. The attributes evaluated were color, taste, consistency and overall liking, through a 9-point hedonic scale ( 1 = extremely dislike, $9=$ extremely like $)$ (Stone \& Sidel, 1993). Each taster evaluated the same five jelly formulations on each day.

Each taster assessed, on average, 5 grams of each of the jelly formulations which were served in $50 \mathrm{~mL}$ plastic cups coded with 3 digits presented in a monadic manner and in a balanced order (Wakeling \& Macfie, 1995). The test was carried out in individual booths at $25^{\circ} \mathrm{C}$ under white light and ventilation. The tasters were instructed in the use of the hedonic scale and to drink water between samples. The sensory analyses were performed according to the Ethics Committee of the Federal University of Lavras, approval number 1.091.594. The participants were informed about the sensory tests and provided written consent. 


\subsection{Statistical analysis}

To compare the different physalis jellies obtained from different sugars regarding the physicochemical, rheological and sensory characteristics, initially univariate statistical analysis (ANOVA) and the Tukey mean test were used to verify if there was a difference between samples at a significance level of 5\% $(\mathrm{p} \leq 0.05)$.

To correlate the physicochemical and textural characteristics with different jelly formulations, the physicochemical and texture data were also analyzed by principal component analysis (PCA). Data were arranged in a matrix of 6 lines (samples) and 11 columns (physicochemical and texture parameters). Data were standardized (correlation matrix) and PCA was applied.

For better understanding and visualization of sensory acceptance of the samples evaluated in the two days, a multivariate statistical analysis was performed, which considers the individuality of consumers and not only the average consumer group that evaluated the product. PARAFAC procedures for three-way internal preference mapping were performed (Nunes et al. 2011). A three-way array was arranged from stacked matrices (consumer x samples) of the acceptance attributes. Each individual acceptance matrix of the consumer acceptance attributes was previously standardized (correlation matrix).

For easy viewing of the jelly formulation sensory acceptance and to correlate with the physicochemical and rheological parameters, a 3-way external preference map obtained by PARAFAC (Nunes et al., 2011) was also elaborated. A 3-way array was arranged from matrices of $i$ rows ( $i$ samples) and $j+m$ columns ( $\mathrm{j}$ consumers $+\mathrm{m}$ physicochemical measurements). These matrices were stacked according to k consumer attributes (color, taste, consistency, and overall liking), resulting in the 3 way array with $i, j+m$, and $k$. The individual $i \times j+m$ matrices of the consumer acceptance attributes were previously standardized (correlation matrix). The $\mathrm{i} \times \mathrm{m}$ portion was the same for each $\mathrm{i} \times \mathrm{j}$ portion of the individual matrices. PARAFAC procedures and the construction of a 3-way preference map and 3-way external preference map were previously reported in detail (Nunes et al., 2011).

Data analysis was performed with SensoMaker software version 1.6 (Pinheiro et al., 2013).

\section{Results and discussion}

\subsection{Physicochemical analysis of Physalis Peruviana}

Regarding the physalis size and weight parameters, the Physalis peruviana presented an average length of $71.00 \mathrm{~mm}$, average diameter $16.80 \mathrm{~mm}$ and $2.60 \mathrm{~g}$ of unit mass.

In the case of fruit classification, the Colombian Institute of Technical Standards classifies the physalis fruits in 4 diameter classes: Class "A" - 15-18 mm; Class "B" - 18.1 to $20 \mathrm{~mm}$; Class "C" - from 20.1 to $22 \mathrm{~mm}$; and Class "D" -above $22 \mathrm{~mm}$ (Instituto Colombiano de Normas Técnicas y Certificación, 1999). Our fruits fall into class “B”. According to Muniz et al. (2014), larger diameter fruits produced in Pelotas-RS (Brazil), fit into this class. Importantly, larger fruits may be more attractive for fresh consumption, since the smaller fruits, that are less accepted, are often intended for processing.
The soluble solids in physalis was $10.40{ }^{\circ}$ Brix, the acidity found was $1.00 \mathrm{~g}$ citric acid/100 $\mathrm{g}$, the ratio was 10.40 and the $\mathrm{pH}$ reached 3.50. These parameters are extremely important as they indicate the ultimate destination of fruits, consumption in fresh or processed form. The soluble solids content and acidity are the main characteristics used for the evaluation of internal quality of the fruit. In this study, the soluble solids content is expressed in ${ }^{\circ}$ Brix, which represents an estimate of the sugar content, besides organic acids, soluble amino acids and pectin (Silva et al., 2002). The fruits with the highest possibility of acceptance are those that have higher soluble solids levels and high sugar content. In general physalis presented high soluble solids content and the level found is in accordance to Bravo et al. (2015) which was in the range of $10.00^{\circ}$ Brix.

Acidity is one of the factors that compromise the classification of fruits based on flavor, fruit with acidity levels ranging from 0.08 to $1.95 \%$ can be classified as mild in flavor and are well accepted for consumption as fresh fruit (Paiva et al., 1997). The physalis evaluated fall into this group. These acidity values are lower than those found by Bravo et al. (2015) which were in the range of $1.88 \pm 0.39 \%$. The acidity demonstrates that physalis is a fruit with a high probability of acceptance for fresh consumption and at the same time through the $\mathrm{pH}$ value we found that it also has good processing potential.

One of the most used ways to assess fruit flavor is through the TSS (total soluble solids)/TA (total acidity) relation (ratio) (Antunes et al., 2010). The higher values for this variable is due to the high soluble solids level and low acidity level, wherein the higher the ratio, the higher the sweetness of the fruit relative to its acidity, which usually reflects in higher sensory acceptance. The physalis presented a high ratio (10.40), a value higher than those found by Narváez-Cuenca et al. (2014) who found values in the range from $7.8 \pm 0.1$ to $9.2 \pm 0.5$.

Regarding the fruit firmness, physalis showed resistance of $3.40 \mathrm{~N}$. During the assessments it was observed that the fruits softened very quickly, showing an overall abundant firmness reduction $12 \mathrm{~h}$ after harvest. The firmness reduction is a process associated with ripening - the faster the firmness loss the lower the shelf life of the fruit.

As to the coloration of physalis fruits, the color parameter $\mathrm{L}^{*}$ was $64.30, \mathrm{~b}^{\star} 47.00$ and $\mathrm{a}^{*} 77.20$. The $\mathrm{L}^{\star}$ values were higher than those found by Singh et al. (2014), and the $b^{\star}$ parameter was similar. The Croma value was 90.38 and hue was 58.76. There are several methods to establish the most appropriate physalis harvest time, however, the coloration is the characteristic most frequently used by agricultural producers and dealers. In post-harvest handling, particular attention should be paid to color, firmness and organoleptic characteristics of the fruit (Muniz et al., 2014).

\subsection{Physicochemical and rheological properties of the physalis jellies}

The average values and the average test of the physicochemical and rheological properties evaluated for the different physalis jelly formulations are shown in Table 1 and Table 2. Except for total acidity, all parameters were significant $(\mathrm{p} \leq 0.05)$ for the jelly made with different types of sugar. In order to facilitate 
Table 1. Soluble Solids (SS), total acidity (TA), $\mathrm{pH}$ and color $\left(\mathrm{L}^{\star}, \mathrm{a}^{\star}\right.$ and $\left.\mathrm{b}^{\star}\right)$, Chroma and ${ }^{\circ} \mathrm{Hue}$ in physalis jellies obtained from different sugars.

\begin{tabular}{lcccccccc}
\hline \multicolumn{1}{c}{ Sugars } & SS ( ${ }^{\circ}$ Brix $)$ & TA (\%) & $\mathrm{pH}$ & $\mathrm{L}^{*}$ & $\mathrm{a}^{*}$ & $\mathrm{~b}^{*}$ & Chroma & Hue \\
\hline White Refined Sugar & $76.67^{\mathrm{b}}$ & $0.13^{\mathrm{a}}$ & $3.20^{\mathrm{b}}$ & $36.19^{\mathrm{a}}$ & $4.32^{\mathrm{b}}$ & $6.14^{\mathrm{b}}$ & $7.51^{\mathrm{ab}}$ & $51.36^{\mathrm{ab}}$ \\
White Crystal Sugar & $66.00^{\mathrm{c}}$ & $0.09^{\mathrm{a}}$ & $3.43^{\mathrm{b}}$ & $37.93^{\mathrm{a}}$ & $4.32^{\mathrm{b}}$ & $9.82^{\mathrm{a}}$ & $10.72^{\mathrm{a}}$ & $68.97^{\mathrm{a}}$ \\
Demerara Sugar & $63.33^{\mathrm{c}}$ & $0.11^{\mathrm{a}}$ & $3.23^{\mathrm{b}}$ & $37.22^{\mathrm{a}}$ & $5.44^{\mathrm{a}}$ & $9.26^{\mathrm{a}}$ & $10.74^{\mathrm{a}}$ & $64.06^{\mathrm{a}}$ \\
Brown Sugar & $86.33^{\mathrm{a}}$ & $0.13^{\mathrm{a}}$ & $4.03^{\mathrm{a}}$ & $29.22^{\mathrm{b}}$ & $1.86^{\mathrm{d}}$ & $-1.37^{\mathrm{c}}$ & $2.42^{\mathrm{c}}$ & $36.58^{\mathrm{b}}$ \\
Coconut Sugar & $66.33^{\mathrm{c}}$ & $0.09^{\mathrm{a}}$ & $4.07^{\mathrm{a}}$ & $33.83^{\mathrm{ab}}$ & $3.02^{\mathrm{c}}$ & $-0.28^{\mathrm{c}}$ & $5.98^{\mathrm{ab}}$ & $6,87^{\mathrm{c}}$ \\
\hline
\end{tabular}

Mean values with common letters in the same column indicate that there is no significant difference among samples ( $\mathrm{p} \leq 0.05)$ by Tukey's mean test.

Table 2. Texture parameters of the physalis jellies obtained from different sugars.

\begin{tabular}{lcccccc}
\hline \multicolumn{1}{c}{ Sugars } & Hard & Adhe & Spr & Cohe & Gum & Chew \\
\hline White Refined Sugar & $0.096^{\mathrm{b}}$ & $0.333^{\mathrm{a}}$ & $0.960^{\mathrm{b}}$ & $0.439^{\mathrm{bc}}$ & $0.042^{\mathrm{b}}$ & $0.04^{\mathrm{b}}$ \\
White Crystal Sugar & $0.057^{\mathrm{b}}$ & $0.029^{\mathrm{c}}$ & $1.587^{\mathrm{b}}$ & $0.574^{\mathrm{bc}}$ & $0.033^{\mathrm{b}}$ & $0.056^{\mathrm{b}}$ \\
Demerara Sugar & $0.089^{\mathrm{b}}$ & $0.224^{\mathrm{b}}$ & $0.957^{\mathrm{b}}$ & $0.413^{\mathrm{c}}$ & $0.037^{\mathrm{b}}$ & $0.036^{\mathrm{b}}$ \\
Brown Sugar & $0.330^{\mathrm{a}}$ & $0.046^{\mathrm{c}}$ & $4.635^{\mathrm{a}}$ & $1.498^{\mathrm{a}}$ & $0.476^{\mathrm{a}}$ & $2.206^{\mathrm{a}}$ \\
Coconut Sugar & $0.079^{\mathrm{b}}$ & $0.080^{\mathrm{c}}$ & $2.078^{\mathrm{b}}$ & $0.755^{\mathrm{b}}$ & $0.060^{\mathrm{b}}$ & $0.155^{\mathrm{b}}$ \\
\hline
\end{tabular}

Hard. - Hardness (N); Adhe - Adhesiveness (N/s); Spr - Springiness; Coh - Cohesiveness; Gum - Gumminess (N); Chew - Chewiness. Mean values with common letters in the same column indicate that there is no significant difference among samples $(\mathrm{p} \leq 0.05)$ by Tukey's mean test.

the visualization, a principal component analysis (PCA) was generated to correlate the physicochemical parameters and texture data with the physalis jellies obtained from different sugars (Figure 1).

Regarding the soluble solids, although all formulations underwent almost the same processing time aiming to reach $65^{\circ}$ Brix, PCA (Figure 1) and the averages table (Table 1) show that the jelly produced with brown sugar stood out from the others as the jelly with highest soluble solids content ( $\left.86.33^{\circ} \mathrm{Brix}\right)$.

The jelly pH ranged from 3.20 to 4.07 and the total acidity varied from 0.09 to $0.13 \mathrm{~g}$ citric acid/ $100 \mathrm{~g}$ (Table 1). According to the PCA (Figure 1) and Table 1 it can be seen that jellies produced with the brown sugar and coconut sugar characterized by presenting higher $\mathrm{pH}$ values, whereas the jellies made with the brown and refined sugars had higher acidity.

Regarding color, the color parameter $\mathrm{L}^{*}$ varied from 29.22 to 37.93 , the $\mathrm{a}^{*}$ color parameter ranged from 1.86 to 5.44 and the color parameter $\mathrm{b}^{*}$ ranged from -1.37 to 9.82 (Table 1 ). As such, the Chroma ranged from 2.42 to 10.74 and the hue ranged from 6.87 to 68.97. According to the PCA (Figure 1) and Table 1 it can be seen that jellies produced with white crystal sugar, white refined sugar and demerara sugar showed the highest $L^{*}, a^{*}, b^{*}, C^{*}$ and hue. That is, they were the clearest jelly formulations and with greater red/yellow intensity coloration. As expected, the jellies elaborated from the brown and coconut sugar stood out for being darker than the others and because of the color parameter $b^{*}$ value presented, it is clear that the fruit color (orange/yellow) was uncharacteristic.

Regarding texture, PCA (Figure 1) and the average table (Table 2) demonstrate that the jelly produced with brown sugar showed the highest values for almost every texture attribute, i.e. this formulation characterized presented a higher hardness $(0.330 \mathrm{~N})$, springiness (4.635), cohesiveness (1.498), gumminess and (0.476) chewiness (2.206). The jelly obtained from the white refined sugar and demerara sugar (Figure 1 and Table 2) characterized by having the highest adhesiveness modulus value (0.224).

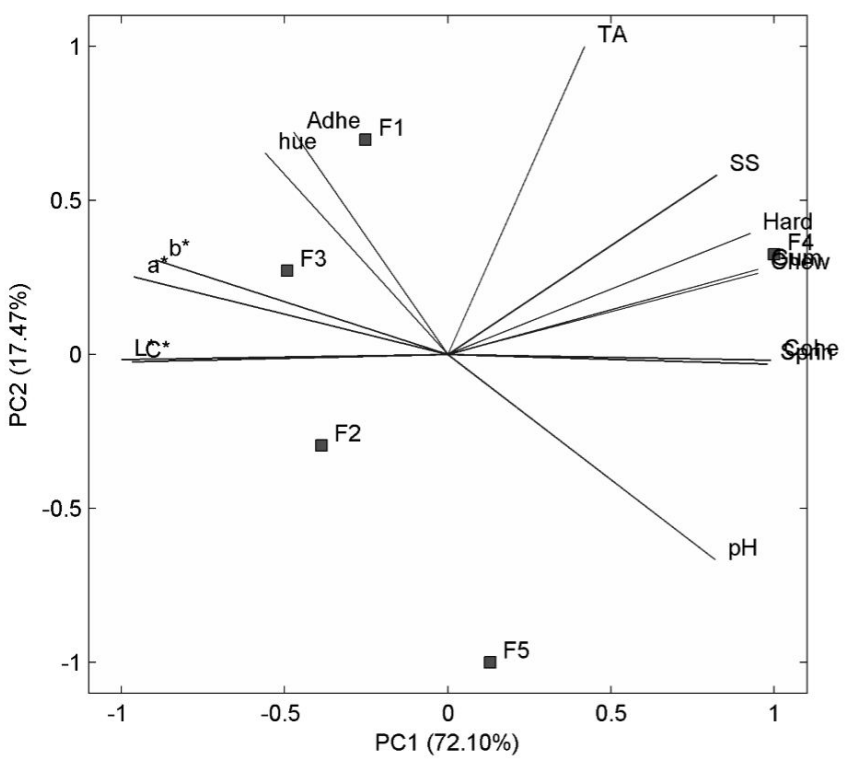

Figure 1. Principal Component Analysis (PCA) for the different samples of physalis jelly and physicochemical and texture properties. White Refined Sugar (F1); White Crystal Cristal (F2); Demerara Sugar (F3); Brown Sugar (F4); Coconut Sugar (F5); Total acidity (TA), g citric acid/100 g fw; total sugar (TS), g/100 g fw. Hard., Hardness (N); Adhe., Adhesiveness (N/s); Sprin, Springiness; Cohe, Cohesiveness; Gummi, Gumminess (N); Chew, Chewiness.

The hardness measures the force required to achieve a given deformation, the springiness measures the speed at which the deformed material is returned to its original condition after the removal of the deforming force, the cohesiveness measures the extent to which the material can be stretched before breaking irreversibly, gumminess measures the energy required to disintegrate one semi-solid food to the point of being swallowed and chewiness reflects the energy required to chew one solid food to the point of being swallowed (Bourne, 1968; Van Vliet, 1991). Thus, brown sugar gives rise to a firmer, more rigid, elastic and 
gummy jelly. This fact can be explained by the characteristics of the sugar, due to the composition and possibly due to the higher mineral content which can lead to a firmer gel.

Adhesiveness measures amount of force to simulate the work necessary to overcome the attractive forces between the food surface and the surface in contact with it (Bourne, 1968; Van Vliet, 1991). Thus, the jellies prepared from white refined sugar and demerara sugars were the most adhesive formulations.

\subsection{Sensory analysis of the physalis jellies}

Through analysis of variance a significant difference was verified among the physalis jellies obtained from different sugars for all the evaluated sensory attributes $(p \leq 0.05)$, however significant difference in acceptance of jellies on different days $(\mathrm{p} \leq 0.05)$ was almost not verified (with and without information about the sugar added in a given formulation). The mean scores and the mean test for the sensory characteristics evaluated in physalis jelly formulations on both days are shown in Table 3 . Figure 2 shows the 3 -way internal preference map that represents the distribution of consumers, samples and consumer sensory attributes on the both days of analysis.

In general, the jelly formulations showed good/intermediate sensory acceptance for all sensory attributes during the two days of evaluations, with average scores situated between the hedonic terms "dislike moderately" and "liked very much" (Table 3).

Through PARAFAC (Figure 2) and the average table (Table 3) it can be seen that jellies prepared with brown sugar and coconut sugar were the least accepted for all sensory attributes evaluated, presenting average acceptance scores situated between "disliked moderately" and "liked slightly", while the other formulations (white crystal, white refined and demerara sugars) were the most widely accepted, with higher average acceptance scores, situated between the terms" liked slightly" and "liked very much".

Regarding the sensory acceptance of the same formulations when consumers had access to information on the type of sugar used and its health benefits, the average table (Table 3) and PARAFAC (Figure 2) show that the sensory acceptance of all the jellies for all sensory attributes evaluated practically remained unchanged. Its mean that the information of the kind of sugar did not influence the sensory acceptance of physalis jelly. Thus, there is evidence that in certain products, such as the case of physalis jelly, sensory acceptance is basically related to the sensory attributes of the product and not the nutritional characteristics and health benefits.
In general, the most nutritious sugars (brown sugar and coconut sugar) did not result in jellies with good sensory quality, however, it is noticeable that white crystal and white refined sugars, typically used in jam and jelly elaboration, could easily be replaced by demerara sugar, which has higher quality and leads to jellies as sensorially accepted as the traditional.

Aiming at correlating sensory acceptance of the first day with the physicochemical and rheological attributes of physalis jellies obtained from different sugars, the external preference map of the overall impression attribute is presented in Figure 3. The 3-way external map represents the distribution of consumers, samples, consumer sensory attributes related to acceptance of the first day and physicochemical and texture properties.

Thought TWEPM (Figure 3 ) and the average table for sensory acceptance and physicochemical parameters (Tables 2 and 3) of physalis jelly formulations, it can be seen that the most accepted jellies (White Refined Sugar-F1; White Crystal Sugar -F2 and

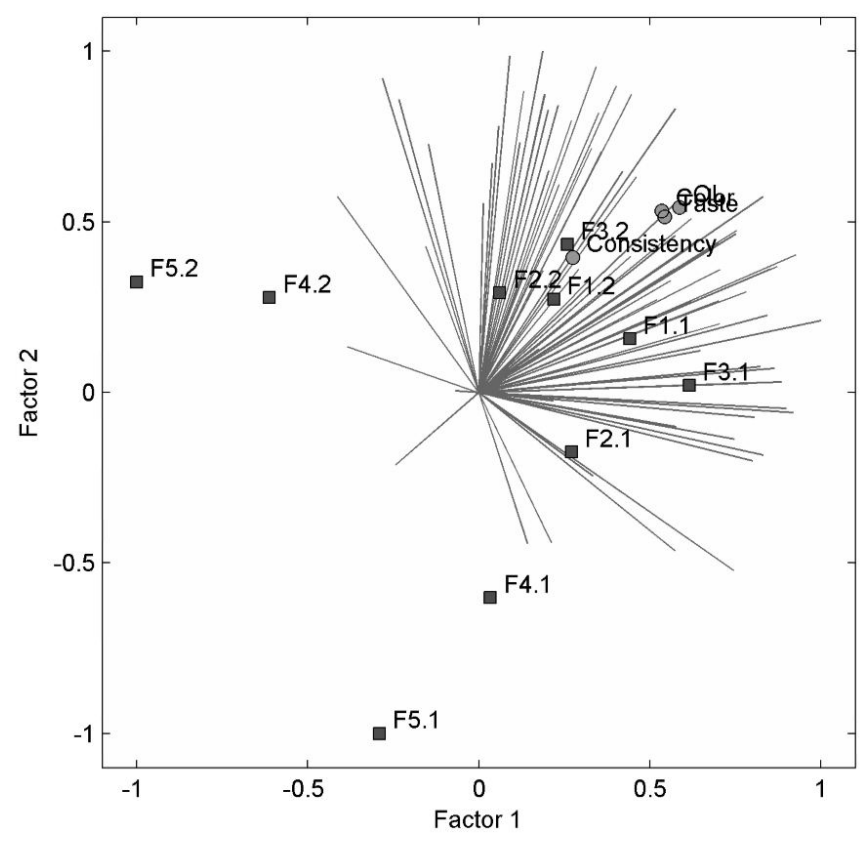

Figure 2. Three-way internal preference maps for color, taste, consistency and overall liking obtained for the physalis jellies obtained with different sugars analyzed on two days. Consumers are represented by vectors, samples by squares and acceptance attributes by circles. White Refined Sugar (F1); White Crystal Cristal (F2); Demerara Sugar (F3); Brown Sugar (F4); Coconut Sugar (F5).

Table 3. Sensory characteristics of the physalis jellies obtained from different sugars analyzed in two days.

\begin{tabular}{|c|c|c|c|c|c|c|c|c|}
\hline \multirow{2}{*}{ Sugar Types } & 1st day & 2nd day & 1st day & 2nd day & 1st day & 2nd day & 1st day & 2nd day \\
\hline & \multicolumn{2}{|c|}{ Color } & \multicolumn{2}{|c|}{ Taste } & \multicolumn{2}{|c|}{ Consistency } & \multicolumn{2}{|c|}{ Overall Liking } \\
\hline White Crystal Sugar & $7.31^{\mathrm{aB}}$ & $7.79^{\mathrm{a} A}$ & $6.82^{\mathrm{abA}}$ & $7.04^{\mathrm{aA}}$ & $6.30^{\mathrm{bB}}$ & $6.89^{\mathrm{abA}}$ & $6.69^{\mathrm{bB}}$ & $7.11^{\mathrm{a} \mathrm{A}}$ \\
\hline Brown Sugar & $5.37^{\mathrm{bA}}$ & $5.78^{\mathrm{bA}}$ & $6.0^{\mathrm{Ba}}$ & $6.03^{\mathrm{bA}}$ & $6.56^{\mathrm{bA}}$ & $6.90^{\mathrm{abA}}$ & $5.91^{\mathrm{cA}}$ & $6.10^{\mathrm{bA}}$ \\
\hline Coconut Sugar & $4.75^{\mathrm{bB}}$ & $5.56^{\mathrm{bA}}$ & $4.40^{\mathrm{cA}}$ & $5.03^{\mathrm{cA}}$ & $6.47^{\mathrm{bA}}$ & $6.79^{\mathrm{bA}}$ & $4.89^{\mathrm{dA}}$ & $5.41^{\mathrm{cA}}$ \\
\hline
\end{tabular}

Mean values with common lowercase letters in the same column indicate that there is no significant difference among samples (p $\leq 0.05$ ) by Tukey's mean test. Mean values with common uppercase letters on the same line indicate that there is no significant difference among samples ( $\mathrm{p} \leq 0.05)$ by Tukey's mean test. 


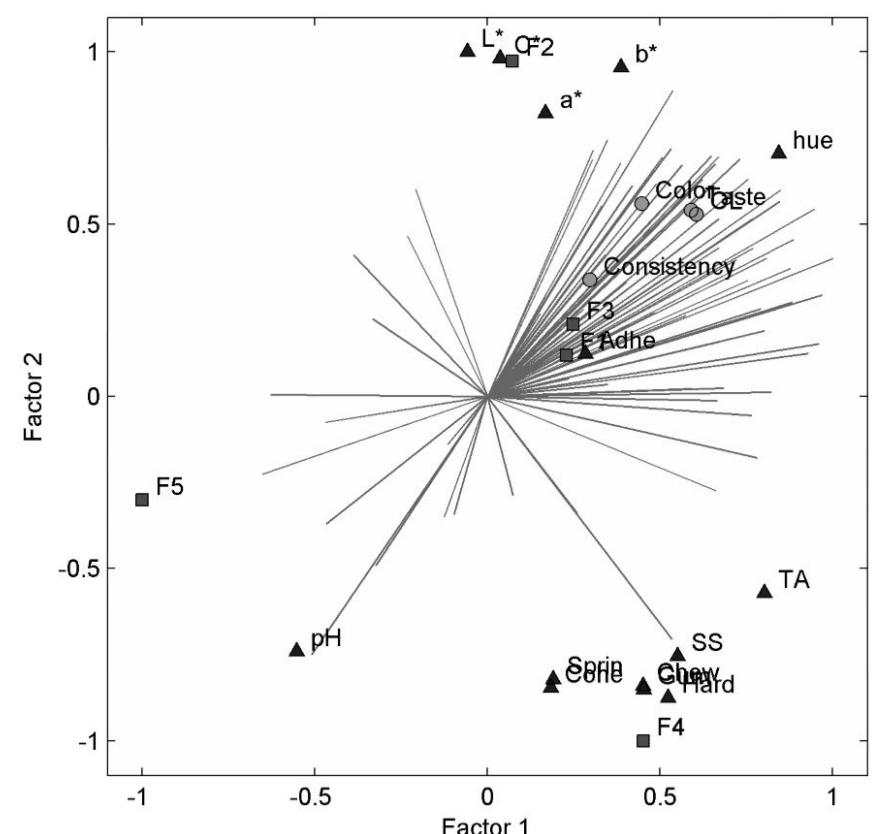

Figure 3. Three-way external preference map (TWEPM) for sensory attributes (color, taste, consistency and overall liking [OL]) and physicochemical properties (color $\mathrm{L} *, \mathrm{a} *, \mathrm{~b} *, \mathrm{C}^{\star}$ and hue, $\mathrm{pH}$, total acidity [TA], and soluble solids [SS], hardness [Hard], adhesiveness [Adhe], springiness [Sprin], cohesiveness [Cohe], gumminess [Gummi] and chewiness [Chew]) for the physalis jellies obtained with different sugars. White Refined Sugar (F1); White Crystal Cristal (F2); Demerara Sugar (F3); Brown Sugar (F4); Coconut Sugar (F5); Total acidity (TA), g citric acid/100 g fw; soluble solids (SS), ${ }^{\circ}$ Brix. Hard., Hardness (N); Adhe., Adhesiveness (N/s); Sprin, Springiness; Cohe, Cohesiveness; Gummi, Gumminess (N); Chew, Chewiness.

Demerara Sugar-F3) were basically characterized by being clearer and with greater red/yellow color intensity formulations. The least accepted jellies (Brown Sugar-F4 and Coconut Sugar-F5) were characterized by being darker and have higher $\mathrm{pH}$ values, and therefore are less acidic. Furthermore, the formulation obtained from the brown sugar (F4) was characterized as having the highest total soluble solids and the highest texture parameter values. Thus, it can be seen that the consumer prefers a clear jelly and consequently one with the most characteristic color of the fruit, in the case physalis and, moreover, has a preference for jellies less sweet, more acidic and softer.

\section{Conclusions}

The type of sugar greatly influences the physicochemical and rheological characteristics of physalis jelly which reflects in product acceptability differences. Due to higher sensory acceptance of white crystal sugar, white refined sugar and demerara sugars are the most suitable for processing in the form of jelly. Information on the type of sugar and its benefits did not influence the sensory acceptance of physalis jelly. The consumers have a preference for a clearer/brighter jelly and consequently those with the most characteristic color of the fruit and, moreover, have a preference for less sweet jellies, more acidic and softer.

\section{Acknowledgements}

To FAPEMIG, CNPq and CAPES for the financial support.

\section{References}

Antunes, L. E. C., Ristow, N. C., Krolow, A. C., Carpenedo, S., \& Reisser, C., Jr. (2010). Yield and quality of strawberry cultivars. Horticultura Brasileira, 28(2), 222-226. http://dx.doi.org/10.1590/ S0102-05362010000200015.

Apriyantono, A., Aristyani, A., Nurhayati, L. Y., Budiyanto, S. \& Soekarto, S. T. (2002). Rate of browning reaction during preparation of coconut and palm sugar. International Congress Series, 1245, 275-278.

Asikin, Y., Hirose, N., Tamaki, H., Ito, S., Oku, H., \& Wada, K. (2016). Effects of different drying-solidification processes on physical properties, volatile fraction, and antioxidant activity of non-centrifugal cane brown sugar. LWT -. Food Science and Technology, 66, 340-347.

Asikin, Y., Kamiya, A., Mizu, M., Takara, K., Tamaki, H., \& Wada, K. (2014). Changes in the physicochemical characteristics, including flavour components and Maillard reaction products, of non-centrifugal cane brown sugar during storage. Food Chemistry, 149, 170-177. PMid:24295691. http://dx.doi.org/10.1016/j.foodchem.2013.10.089.

Bourne, M. C. (1968). Texture profile of ripening pears. Journal of Food Science, 33(2), 223-226. http://dx.doi.org/10.1111/j.1365-2621.1968. tb01354.x.

Bravo, K., Sepulveda-Ortega, S., Lara-Guzman, O., Navas-Arboleda, A. A., \& Osorio, E. (2015). Influence of cultivar and ripening time on bioactive compounds and antioxidant properties in Cape gooseberry (Physalis peruviana L.). Journal of the Science of Food and Agriculture, 95(7), 1562-1569. PMid:25131258. http://dx.doi. org/10.1002/jsfa.6866.

Friedman, H. H., Whitney, J. E., \& Szczesniak, A. S. (1963). The texturometer: a new instrument for objective texture measurement. Journal of Food Science, 28(4), 390-396.

Gennadios, A., Weller, C. L., Hanna, M. A., \& Froning, G. W. (1996). Mechanical and barrier properties of egg albumen films. Journal of Food Science, 61(1), 585-589. http://dx.doi.org/10.1111/j.1365-2621.1996. tb13164.x.

Instituto Adolfo Lutz - IAL. (2005). Normas analíticas do Instituto Adolfo Lutz. São Paulo: IAL.

Instituto Colombiano de Normas Técnicas y Certificación - ICONTEC. (1999). NTC 4580: Frutas frescas. Uchuva. Especificaciones. Bogotá: ICONTEC.

Jackix, M. H. (1988). Doces, geleias e frutas em calda (pp. 158). São Paulo: Icone.

Jaffé, W. R. (2012). Health effects of Non-Centrifugal Sugar (NCS): a review. Sugar Technology, 14(2), 87-94. http://dx.doi.org/10.1007/ s12355-012-0145-1.

Mendonça, C. R., Rodrigues, R. S., \& Zambiazi, R. C. (2000). Açúcar mascavo em geleiadas de maçã. Ciência Rural, 30(6), 1053-1058. http://dx.doi.org/10.1590/S0103-84782000000600022.

Muniz, I. J., Kretzschmar, A. A., Rufato, L., Pelizza, T. R., Rufato, A. R., \& Macedo, T. A. (2014). General aspects of physalis cultivation. Ciência Rural, 44(6), 964-970. http://dx.doi.org/10.1590/S010384782014000600002 .

Narváez-Cuenca, C. E., Mateus-Gómez, A., \& Restrepo-Sánchez, L. P. (2014). Antioxidant capacity and total phenolic content of air-dried cape gooseberry (Physalis peruviana L.) at different ripeness stages. Postharvest Physiology and Technology, 32(1), 232-237. http://dx.doi. org/10.15446/agron.colomb.v32n2.43731. 
Nunes, C. A., Pinheiro, A. C. M., \& Bastos, S. C. (2011). Evaluating consumer acceptance tests by three-way internal preference mapping obtained by parallel factor analysis (PARAFAC). Journal of Sensory Studies, 26(2), 167-174. http://dx.doi.org/10.1111/j.1745459X.2011.00333.x.

Paiva, M. C., Manica, I., Fioravanço, J. C., \& Kist, H. (1997). Caracterização química dos frutos de quatro cultivares e de duas seleções de goiabeira. Revista Brasileira de Fruticultura, 19(1), 57-63. http:// dx.doi.org/10.1590/S0100-29452002000100061.

Pinheiro, A. C. M., Nunes, C. A., \& Vietoris, V. (2013). SensoMaker: a tool for sensorial characterization of food products. Ciência $e$ Agrotecnologia, 37(3), 199-201. http://dx.doi.org/10.1590/S141370542013000300001.

Riedel, R., Bohme, B., \& Rohm, H. (2015). Development of formulations for reduced-sugar and sugar-free agar-based fruit jellies. International Journal of Food Science \& Technology, 50(6), 1338-1344. http:// dx.doi.org/10.1111/ijfs.12787.

Rodrigues, E., Rockenbach, I. I., Cataneo, C., Gonzaga, L. V., Chaves, E. S., \& Fett, R. (2013). Minerals and essential fatty acids of the exotic fruit Physalis peruviana L. International Journal of Food Science \& Technology, 29(3), 642-645. http://dx.doi.org/10.1590/ S0101-20612009000300029.

Rodrigues, R. S., Galli, D. C., \& Machado, M. R. G. (1998). Comparação entre seis marcas de açúcar mascavo. In Anais do $2^{\circ}$ Congreso Latinoamericano De Ingeniería Rural, La Plata; Anais do $5^{\circ}$ Congreso Argentino De Ingeniería Rural, La Plata.

Silva, P. S. L., As, W. R., Mariguele, K. H., Barbosa, A. P. R., \& Oliveira, O. F. (2002). Distribuição do teor de sólidos solúveis totais em frutos de algumas espécies de clima temperado. Revista Caatinga, 15(2), 19-23. http://dx.doi.org/10.1590/S0100-29452013000200027.

Singh, D. B., Ahmed, N., Lal, S., Mirza, A., Sharma, O. C., \& Pal, A. A. (2014). Variation in growth, production and quality attributes of Physalis species under temperate ecosystem. Fruits, 69(1), 31-40. http://dx.doi.org/10.1051/fruits/2013099.

Souza, V. R., Pereira, P. A. P., Pinheiro, A. C. M., Bolini, H. M. A., Borges, S. V., \& Queiroz, F. (2013). Analysis of various sweeteners in low- sugar mixed fruit jam: equivalent sweetness, time intensity analysis and acceptance test. International Journal of Food Science \& Technology, 48(7), 1541-1548. http://dx.doi.org/10.1111/ijfs.12123.

Stone, H. S., \& Sidel, J. L. (1993). Sensory evaluation practices. San Diego: Academic Press.

Struck, S., Jaros, D., Brennan, C. S., \& Rohm, H. (2014). Sugar replacement in sweetened bakery goods. International Journal of Food Science \& Technology, 49(9), 1963-1976. http://dx.doi.org/10.1111/ijfs.12617.

Takimoto, T., Kanbayashi, Y., Toyoda, T., Adachi, Y., Furuta, C., Suzuki, K., Miwa, T., \& Bannai, M. (2014). 4 $\beta$-hydroxywithanolide E isolated from Physalis pruinosa calyx decreases inflammatory responses by inhibiting the NF- $\mathrm{BB}$ signaling in diabetic mouse adipose tissue. International Journal of Obesity, 8(11), 1432-1439. PMid:24566854. http://dx.doi.org/10.1038/ijo.2014.33.

Van Vliet, T. (1991). Terminology to be used in cheese rheology. Bulletin of the International Dairy Federation, 268, 5-15.

Wakeling, I. N., \& Macfie, H. J. H. (1995). Designing consumer trials balanced for first and higher orders of carry-over effect when only a subset of k samples from t may be tested. Food Quality and Preference, 6(4), 299-308. http://dx.doi.org/10.1016/0950-3293(95)00032-1. 